\title{
REMARKS ON STATISTICAL DISTRIBUTION OF INTENSITY OF CHANCE DAMAGES
}

\author{
Antoni Banasinski and Antoni Wanatowski, \\ Warsaw (Poland)
}

Actuaries of Polish National Insurance are in the happy position that they have at their disposal a wealth of complete statistics which permits study of the level of chance damage (the loss-rate) and its elements such as frequency of occurrence, spread, intensity, etc. This welcomed situation stems from the fact that in Poland there is general insurance in certain sectors of the national economy. For instance, in the case of cooperative and individual (private) farms the entire property (buildings, products, livestock, real estate and machines, household furniture, etc.) is insured according to uniform principles against all hazards-fire, winds, floods, hail, death of animals and others.

This, among other things, makes possible the statistical determination of the intensity of chance damages (i.e. the extent of damage to a given object during one accident) in various elements of farm property.

Studies of this type have been of great practical importance in the activities of Polish National Insurance, first and foremost in the reconstruction of the insurance rates in connection with a change in the system to the "first risk" system (employed almost exclusively at present in farm insurance). Moreover, it is interesting that these studies have also served as auxiliary material in the elaboration of the optimum programme for the utilization of the funds allocated for preventing chance damages.

Studies on the distribution of the intensity of chance damages on insured objects have led to interesting results which have confirmed once again that this distribution is dependent on the structure of the objects insured and on the risks (hazards) covered by insurance protection; any hypotheses concerning these distributions must be verified in each case by trial statistical studies. 
Without going into the theoretical angle of this subject at this point, we wish to present one table containing the results of statistical studies concerning the extent of fire damage to rural buildings in Poland; these buildings are classified according to construction, primarily wood or brick or stone, and according to purpose, residential or farm buildings. In presenting as an example the statistical data for the years I957-59 on the intensity of fire damage to rural buildings, we refer to similar information published earlier in the reports from the International Congress of Actuaries *):

Comparison of data based on statistical materials for $1957-59$

Rural buildings damaged by fire, 1957-1959, classified according to percentage of damage, construction and purpose

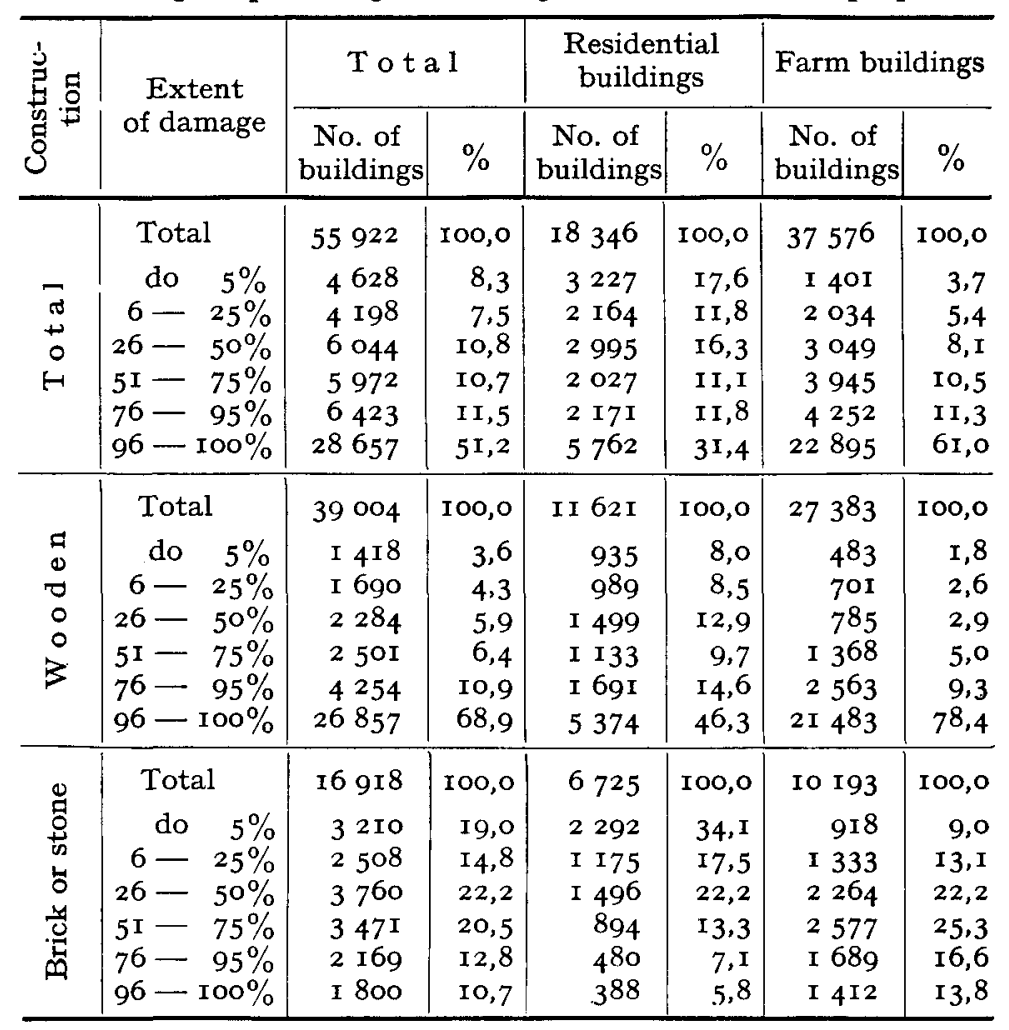

*) Transactions of the Eleventh International Congress of Actuaries in Paris, Vol. II, O. Einfield (Warsaw) : Beitrag zur Statistik der Gebäudefeuerversicherung (pp. 427-434). 


\section{Graphic representation of distribution of intensity of fire damage to rural buildings}
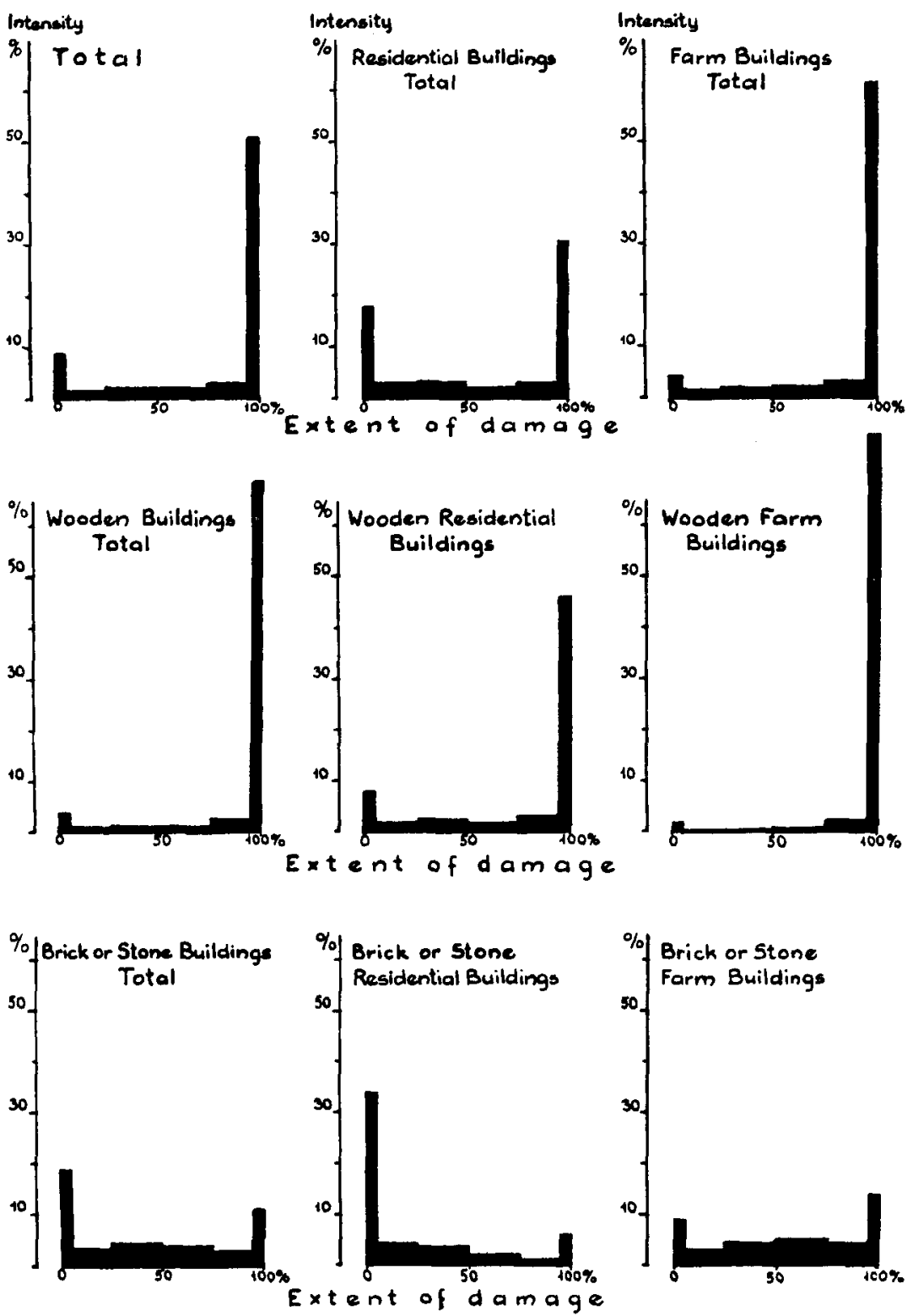
with data for the same country for I934-39 permits us to draw conclusions as to the time-variation in the distribution of intensity of fire damage. This is a highly interesting problem since it is connected with analysis of the extent of changes in the collectivity of the insured objects (changes in construction, increase in fire safety, changes in socio-economic conditions, etc.) that affects the degree of inflammability and its elements.

Analysis of the presented results of statistical studies of the intensity of chance damages in rural buildings is by-passed here. We merely draw attention to the fact that the distribution of fire damage in wooden buildings is a typical example of extreme asymmetrical distribution, i.e. in the shape of the letter "J", and the distribution of intensity of fire damage in brick or stone buildings is U-shaped.

It is not difficult to explain why the intensity of fire damages is so distributed. 